\title{
Applied Research Training Model of Employment-oriented Financial Management
}

\author{
Jiangang LI \\ Weifang University of Science and Technology \\ Shouguang,Weifang,Shandong, 262700 China
}

\begin{abstract}
-employment-oriented financial management training objectives are as the basis to explain the need for financial management training applied talents, which is revealing major problems of financial management professional applications that exist in education, training applied talents from abroad to explore the culture Financial Management Applied Talents of ways to effectively promote the development of education in financial management applications.
\end{abstract}

Keywords- Financial Management; Applied Talents; Culture; Employment

\section{INTRODUCTION}

Development of Applied undergraduate education, training application-oriented talents is an urgent task of local institutions of higher education. At present, China's higher education formed the four types of research, teaching research, teaching-oriented colleges and vocational colleges. Research, teaching research institutions is generally the key institutions (that is, into 211 projects, 985 projects of universities), vocational colleges develop technical and vocational education in general, and it is to the teaching institution based teaching model how to develop. In October 2006, the Ministry of Education of the University of Experts was to assess undergraduate assessments, talking about "applied education", the expert said: "The development of the university, it is a strategic challenge to choose teaching as a development road application. The tie solid really move forward, you will find yourself in the tertiary education sector is an important position. "Explore the laws applied talents training; financial management professional full economic and social development needs of the higher education of their own scientific development are important.

\section{A. improve student social adaptation and vocational adaptability to meet the economic and social}

Development needs. Popularization of Higher Education is to promote the restructuring of Applied Higher Education as a type of higher education, it is an important part of the application of the undergraduate education system, it is to economic and social development of high-quality application-oriented talents training mission, is conducive to high quality of financial management applications personnel, training innovative talents. It is establishing corner "characteristics and laws of the activities, and it can explore a kind of by the professional schools to lead to student class (community) or student organizations. It is based on as much as possible to attract more students to participate in the" English Corner "event mechanism innovation" English Corner "event in the form of content and activities. It is to further enhance the" English Corner "event attractiveness and effectiveness by the Youth League and the timely organization of students' English Corner" event to exchange experiences and outstanding (or star), "English Corner" Activity units or activities are named "English Corner" excellent tutors or excellent organizer selection and other activities to promote the "English Corner" activity to flourish.

\section{B. Exploration and practice are on the organization of extracurricular activities in English class competitions.}

Proper English class competition extracurricular activities are for the promotion of students' learning, which can improve the English proficiency of positive significance. However, the extra-curricular activities should not be excessive and indiscriminate, otherwise it will cause backfire. We should be in accordance with the "close to the first class, be close to the students' practical" principle of English toplevel competition classes extracurricular activities designed to make such an extension and complement the activities of the first class, but also more in line with the actual needs of students in order to better serve the training objectives. For example, we shou be closely coordinated with the first class of "English Speech Contest", and "English Dormitory" Create English Contest combines class work and other activities.

\section{APPLIED FINANCIAL MANAGEMENT TRAINING OBJECTIVES}

With the optimization and upgrading of the socialist market economy, companies need more financial staff both for financial management, but also for them to participate in the management of enterprises. The current financial professionals are in training on just a blank, which resulted in financial talent and cultivate market demand out of touch, which is unable to meet the needs of society and business development professional to set up and personnel training is to focus on solving this problem. The purpose of the financial management of education precisely is to the needs of students for career development and professional settings, and students' vocational skills, the students are consistent 
means of livelihood. Thus, changes in the financial management are to the application of professional management personnel, which is an inevitable trend. The application of financial management talent is to break through the traditional financial officer who will pipe was not the steward's ills. The managed financial professionals refer to grasp the system Financial accounting theory and a wealth of management knowledge, familiar with international practices, it is with analytical skills and strategic thinking of complex accounting expertise, and it has the potential to become future corporate management team of experts in finance and accounting. Training goal is the guiding ideology of the teaching process, what kind of training objectives, what kind of culture results are. Colleges and universities in the training target of application management personnel must be accurate: market-oriented management culture cannot only understands but also understand the financial needs of the community. The comprehensive talent training objectives can be expressed as: the training to adapt to socialist modernization needs moral, intellectual, physical comprehensive development, and with management, economic, legal and financial aspects of financial knowledge and ability. The creative financial management of the complex environment of the future has strong adaptability to engage in industrial and commercial finance, financial enterprises, institutions and government departments and financial management applications expertise.

\section{PROBLEMS IN THE FINANCIAL MANAGEMENT TRAINING APPLIED TALENTS}

From the perspective of the financial management of teaching, teaching and their resources are through education, institutions of control in general colleges. It has found that there are problems in the financial management of teaching:

We should focus on teaching theory and ignore the practical ability. Due to the financial management of teaching, it is generally without significant investment in machinery and equipment laboratory equipment. For their resources, the limited funds university is concerned, which can be described as less investment and quick, so the number of admissions is relatively more, the relative shortage of teachers and teaching conditions are relatively simple, Teaching is mainly on the blackboard and multimedia-based teaching. Close schools and classes in general cases, numerous class size, and student interaction is relatively less than normal, with a single student, exchange becomes less, and practical ability is relatively weak.

The importance of learning in schools is to buy, buy offcampus learning contempt action. For practical ability, and we should pay attention to the school manual training school for their actual bills there are various ways by copying, printing into a book. Then cut and paste various instruments, many students and not one by one, with hands-on teaching. And. Private college students motivation is to learn some relatively poor, there are usually not a lot of fundamental exercises, which is directly copied from the original books and vouchers and other students work. And now they have to be copied by a mobile phone camera, the students did their proximity Habitat of feeling, just to deal with the job, and did not really play a role in teaching practice. It is hard to find off-campus internships exist in general that are not willing to receive internship students, followed by the low side internship fees, internships and other conditions are not satisfied, and the school is a burden to bear the cost of the internship. Besides the reality of financial management activities, basically a commercial secret, the general direction of investment, financing and fundraising amount, repayment and return the way so be kept confidential, the real financial management practices are not many internship opportunities, mainly focusing on basic accounting work in practice.

\section{A. Main Courses Occupy Many Hours}

Our higher education, ideological and political education class occupied and foreign language courses are relatively more, this is mainly because the state of ideological and political education more requirements. At the same time, English and other foreign languages occupy more hours, regardless of the students like it or not, there is little to do with the professional, political and ideological education that must be taught a foreign language. The students in private institutions are mainly due to the orientation of training is the actual ability to work, they do not need the latest research abroad for analysis and research, so many students after graduating from basic applications within a foreign language do not need to understand the status of overseas research and cutting-edge technology. Ideological and political education, fundamentally speaking, cannot be separated from social reality. Inter was empty talk, but the need for a fundamental reorganization officialdom, so that students from personal experience make up the sentiment to experience from a variety of social practice, this is not to pay more hours, which can be resolved. Too much empty talk sometimes causes more resentment.

\section{B. students act poorly.}

Due to the impact of China's exam-oriented education model, many students before school have been under high levels of stress, parents and teachers are in the "nanny" services. They are to enter the university suddenly lost control, and it is difficult to adapt themselves actively in learning mode, many students enter college after gave up learning to play and the game of life based. Due to the current economic situation and employment pressure, a lot of college students' views are on the future of an uncertain, that learning is not much better with a lot of people that they graduate with unemployment. Therefore, lack of motivation is to learn. Currently, due to the accounting profession, the financial management professionals do not ask for mathematics and other subjects. And many poor liberal arts students and science students in the mathematical basis of students apply for financial management professional. But due to the high degree of social recognition of financial officers, many parents interest regardless of the child's interests, according to their own ideas, are forcing children to learn financial management professional, which can result in some students are not enthusiastic about an important reason. 


\section{Computer Application Ability is ineffective.}

Now a lot of works are inseparable from the computer, many students for the computer game is very skilled, for real applications, the ability to solve practical problems is very lacking. For example, I found that a specific case in the research, some graduates for the construction of bank statements are to import into Kingdee system for automatic reconciliation of the problem helpless, actually they were manually entered into the accounting software for reconciliation, with twice the power and a half. In fact, the electronic statement conversion data through ExcEL, you can import into Kingdee system to complete the automatic reconciliation. Others, such as according to the industry, you need to take advantage of the unit's current financial management software for secondary development, we should set up a new financial indicators who are all performed extremely layman, many people would not be.

\section{THOUGHTS ON APPLIED TALENTS OF FINANCIAL MANAGEMENT IN UNIVERSITIES}

In response to these problems, the author carried out thinking that can come from the following aspects to perfect.

\section{A. Classes are small; the manual simulation goes into the classroom.}

Split small classes, teachers and beneficial interaction between students, while the manual simulation materials are into the classroom, even before the simulation work, and also it is to explain the financial processing settings scientific. Private institutions will need to vigorously recruit training teachers, expand classroom and laboratory, multimedia and other teaching facilities. It vigorously offers a variety of teaching conditions and improves teaching effectiveness.

\section{B. Encourage the creation of off-campus learning base to buy}

Through a variety of ways with a variety of business linkages, we should develop the practice base, and confidential student education, as far as internships secrecy. Especially accounting firm is financial management expertise with important training base for students more exposure to the financial management practices in an effort to increase the sensory impression comprehend the importance of financial management. It is to improve learning initiative. Their resources, institutions practice bases can be established by way of investment shares, and by way of agreement to achieve the purpose of the base of teaching.

\section{C. increase the proportion of the main courses of instruction.}

For English and other non-major courses, it may be appropriate to reduce teaching hours, the right to reduce the impact on students graduating weight, you can use other ways to perform elective, after all foreign forty-six that are not useful for all students, and there is no impact on graduation. Private colleges do not have to copy the public colleges of foreign language education mode, you cannot even choose a foreign language course, one can be interested in learning to play the initiative based on students' interests, on the other hand, can increase the proportion of main courses taught.

\section{D. mobilize the enthusiasm of students}

Primary and secondary education are basic education, private colleges are vocational and technical education and training is the ability to work, therefore, to determine their own employment and employability direction university education should be taken seriously. Education is putting the cart before the present situation; it should allow students to understand this point: It is now acceptable to determine the future of education is an important milestone in the road of life, rather than mixed with a diploma only.

\section{CONCLUSIONS}

With the optimization and upgrading of the socialist market economy, companies need more financial staff both for financial management, but also for them to participate in enterprise management and financial professionals in the culture when the university is just a blank, which resulted cultivate financial talent out of touch with the market demand. It cannot meet the needs of society and business development, professional settings, and personnel training colleges is to focus on solving this problem, and the purpose of the financial management of education precisely to the needs of students for career development and professional settings and students in vocational skills, students' livelihoods is consistent. Thus, the transition to college financial management professional application management personnel is an inevitable trend.

\section{ACKNOWLEDGEMENTS}

topic name "employment-oriented financial management undergraduate training model innovation research"

\section{References}

[1] Yao Zhenghai. Study employment-oriented financial management application-oriented training model [J] Business Economics, 2013,20: 122-124.

[2] Zhu Yue. February Financial Management Undergraduate Students' Practical Ability Path of [J] Changchun Normal University, 2014,07: 145-146.

[3] Wong Zhong. Thoughts on Applied Talents of Financial Management in Universities [J] providers, 2014,16: 18.

[4] Ji Linlong. Case Teaching in Applied Talents financial management application [J] economist, 2011,03: 140-141.

[5] Wang Huiyuan. Universities of applied Talents of Financial Management [J] providers, 2012,05: 126.

[6] Zhu Zhuanhua. Financial Management Undergraduate Education Applied Talents of [J] education and occupation, 2008,23: 85-86.

[7] Wang Yue. Financial management professionals Application Ability [J]. Private Technology, 2010,12: 115. 